\title{
Disperse reinforcing of alkaline aluminosilicate binders for protection materials of structures
}

\author{
Pavel Krivenko, and Volodymyr Kyrychok ${ }^{*}$
}

Scientific Research Institute for Binders and Materials, Kyiv National University of Construction and Architecture, 03037 Povitroflotskyi Avenue, 31, Kyiv, Ukraine

\begin{abstract}
The review of the literature and the analysis of the problem of durability and reduction of cracking of binders and materials for the protection of building structures have been carried out, an effective method of improving their cracking resistance during the entire lifetime has been proposed. The influence of reinforcement of the matrix of alkaline aluminosilicate binders on their technological and physical-mechanical properties was investigated. According to the study of influence reinforcing components on the properties of binders, it should be noted that the highest the conditional coefficient of crack resistance is characterized by the contents containing in its composition as a reinforcing component of the basalt scales. The microstructure of the connecting substance and the contact zone "compound substance - the reinforcing component" has been analyzed, the type and the optimum amount of the reinforcing component have been established to provide the technological and operational properties of the materials for the protection of building structures.
\end{abstract}

\section{Introduction}

During the operation of building structures in aggressive environments, their durability is sharply reduced due to the diverse nature and origin of corrosion processes.

Building structures constructed in accordance with technical requirements may, for a long time, withstand the negative effects of the atmospheric-climatic and aggressive external environment. In operation, they gradually change their physical, mechanical and structural properties as a result of physico-chemical processes of interaction of cement stone and reinforcement with the external environment [1-3]. Physico-chemical processes passing on the surface of structures in contact with environment, leads to a violation of its functional properties. Therefore, increasing the durability and ensuring the reliable operation of building structures with the help of binders for constructures surfaces is gaining in popularity, and their development is a topical issue of modern materials science.

Protection of building structures by binder on the basis of organic and inorganic substances and their advantages and disadvantages is considered in scientific papers [4-6]. The main drawbacks of organic binders are flammability, aging during the operation, loss of adhesion to the base. The use of modified cements is not effective in view of the low resistance to aggressive media of the matrix, which leads to the destruction of binder.

\footnotetext{
* Corresponding author: v.kyrychok@gmail.com
} 
Scientific School of V.D. Glukhovsky Scientific Research Institute for Binders and Materials (SRIBM) [7-11] proved the possibility of using alkaline aluminosilicate binders (geocements, geopolymers) to protect building structures from the effects of aggressive environments. Alkaline aluminosilicates are characterized by particularly high reliability indices - corrosion resistance, temperature resistance, fire resistance, which is ensured due to synthesis zeolite-like new formations.

In order to provide the conditions of hardening and structural formation of protective binders, their mortar mixture should have optimum filling, sufficient mobility, high thixotropy and water retention capacity. Cracking of binder at these stages is due to shrinkage deformations brcause of the evaporation of water and its absorption by the base. Therefore, provision of optimal conditions at this stage is ensured by the use of polyfraction composition of fillers and organic and mineral modifiers as a part of binder [12].

Cracking of binders at the stage of their exploitation is a result of stresses that arise under the influence of mechanical loads, temperature or moist gradients. When using buildings or structures in an aggressive environment, cracking resistance of protective binders is a basic requirement. For the protection of building structures, this coverage index is particularly important given a possibility of cracking openings during their operation [4].

According to the data [13,14], for the evaluation of the resistance to cracking of composite materials, a conditional coefficient of crack resistance is used, that is, the ratio of compressive strength to its tensile strength at bending. Analysis of work on the resistance to cracks in composite materials shows that with the introduction of reinforcing components into their composition, the physico-mechanical parameters are significantly increased, especially the strength of the composite on bending tension. In order to ensure the overlapping of the cracks, reducing the deformability of the binder and increasing its crack resistance, research is conducted in the direction of searching for methods for its reinforcement. Consequently, the reinforcement of the binders can significantly increase their crack resistance during their lifetime $[15,16]$.

Therefore, the purpose of this work was to study the influence of reinforcing components on the properties of protective alkaline aluminosilicate binders for building structures. To achieve this purpose, the following tasks are set:

- to study the influence of the type of reinforcing components on properties of binders;

- to analyze the formation of reinforced binders structure;

- to determine the optimal number of reinforcing components in the protective binders.

\section{Materials and methods}

According to the analysis of studies $[6,14]$, the following types of reinforcing components are used in the production of effective protective materials for their reinforcement: polypropylene fibers (PPF), basalt fibers (BF) and basalt scales (BS) (Figure 1).

a)

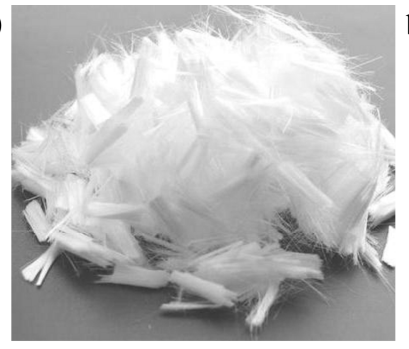

b)

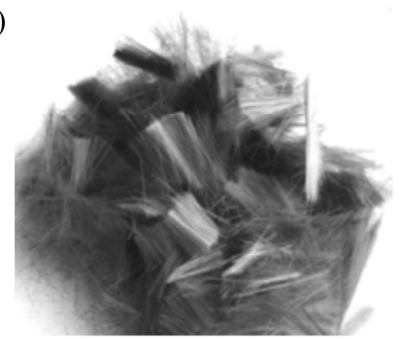

c)

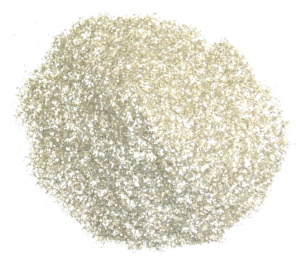

Fig. 1. Reinforcing components for protective binders: a) polypropylene fibers (PPF); b) basalt fibers (BF); c) basalt scales (BS). 
The main indicators of evaluation of reinforcing components influence on the formation of binder structure were selected, physical and mechanical characteristics of the composite and the conditional coefficient of crack resistance, $C_{c r}$, the ratio of flexural $R_{f}$ to compressive $\mathrm{R}_{\mathrm{c}}$ strength. Assessment of binder density was carried out using photographs of composite microstructure, the technological properties of binder were evaluated with dissolution of mortar mixtures.

Before mixing the mortar, the liquid and dry parts of the binder were separately prepared. Optimal composition of the binder was $\left(0.8 \mathrm{Na}_{2} \mathrm{O}+0.2 \mathrm{~K}_{2} \mathrm{O}\right) \mathrm{Al}_{2} \mathrm{O}_{3} \cdot 4.5 \mathrm{SiO}_{2} \cdot 12 \mathrm{H}_{2} \mathrm{O}$ $-40 \%$, and sand $0.315-0.63 \mathrm{~mm}-24.5 \%, 0-0.315 \mathrm{~mm}-21.2$, fly ash $0-0.16 \mathrm{~mm}-14.3 \%$. The liquid part included: the alkaline component and its chemical modifiers, to the dry one - the components of the binding, organic additives and fillers. The support components were injected to a dry portion in an amount of $1-3 \%$ by weight of the binding agent in the mixture, namely the total mass of liquid alkaline component and dry constituent binders. After preparing the liquid and dry parts of the binder, they were thoroughly mixed together using a HOBART mixer, and the dissolution of the mortar mixture was studied, and samples $40 \times 40 \times 160 \mathrm{~mm}$ were formed. The hardening of the binder was carried out for 28 days at a temperature of $20 \pm 2{ }^{\circ} \mathrm{C}$ : the first day in the molds, after which the decomposition and placement of samples in a wet environment were $\mathrm{W}=95 \pm 5 \%$. After hardening of the binder samples, they were tested for compressive and flexural strength, their microstructure was investigated and the conditional coefficient of crack resistance was calculated.

\section{Results and discussion}

The results of tests on the influence of reinforcing components on the properties of binders are given in the form of diagrams in Figures 2-4.

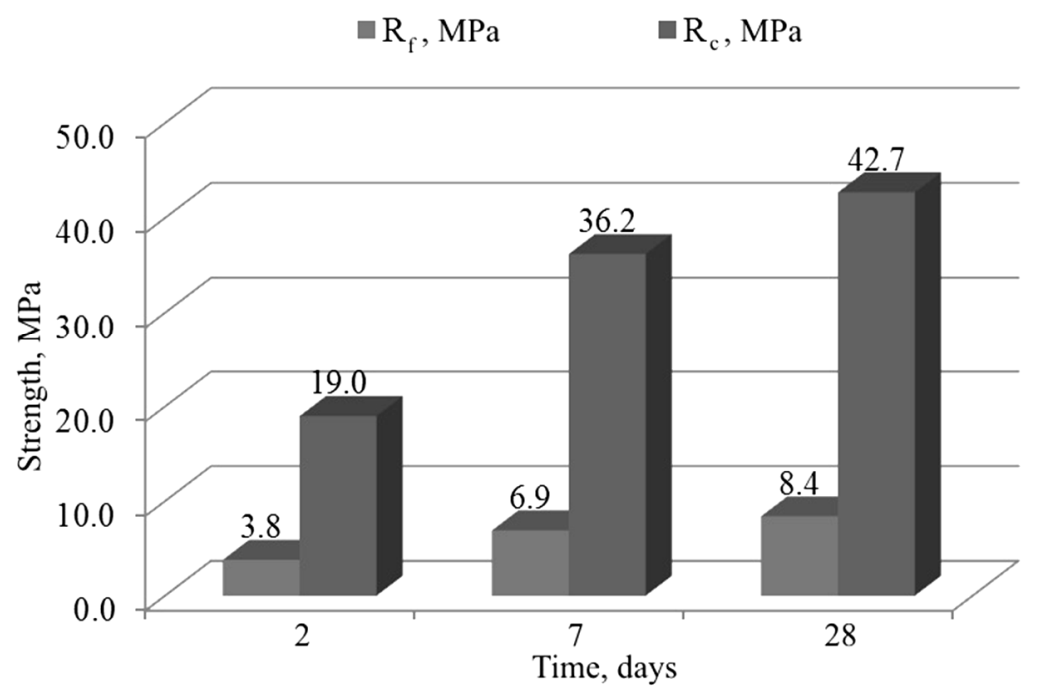

Fig. 2. The effect of adding $1 \%$ polypropylene fibers (PPF) to the binder on its physical and mechanical characteristics.

According to the data shown in Fig. 2 the introduction into the binder of $1 \%$ polypropylene fibers leads to an increase in flexural strength of $4-8 \%$ and a compressive strength of $1 \div 3 \%$. However, the maintenance of PPF in the binder is accompanied by a sharp decrease in the flowability of the mortar mixture. 
Analyzing the influence of basalt fibers on the physical and mechanical characteristics of the binder of rice. 3 , it is worth pointing out that bending strength increases by $8-20 \%$ and compressive strength by $9-16 \%$; the addition of $1 \% \mathrm{BF}$ to the composition also is accompanied by a significant deterioration of the dissolution of the mortar mixture.

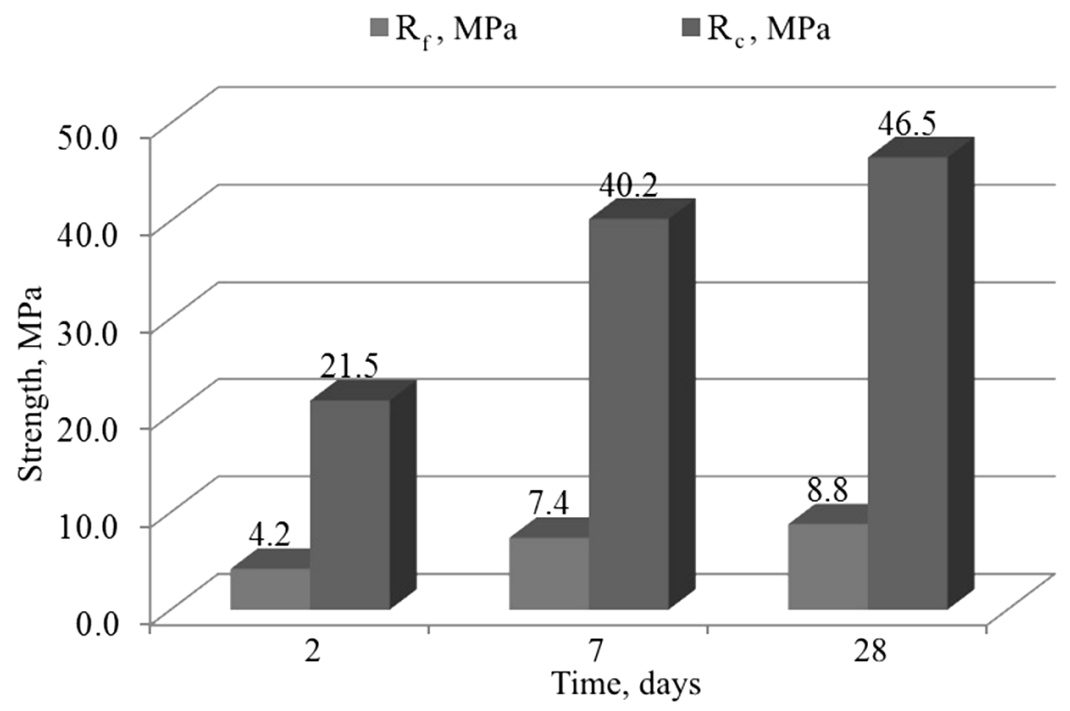

Fig. 3. The effect of adding $1 \%$ basalt fibers (BF) to the binder on its physical and mechanical characteristics.

Adding to be deposited basalt scales according to Figure 4 the main way affects the strength of its bending, increasing it to $14-25 \%$ and compressive strength increased only by $5-10 \%$. Mortar mixture with contents of $1 \%$ BS is characterized by a sufficient index of deformity.

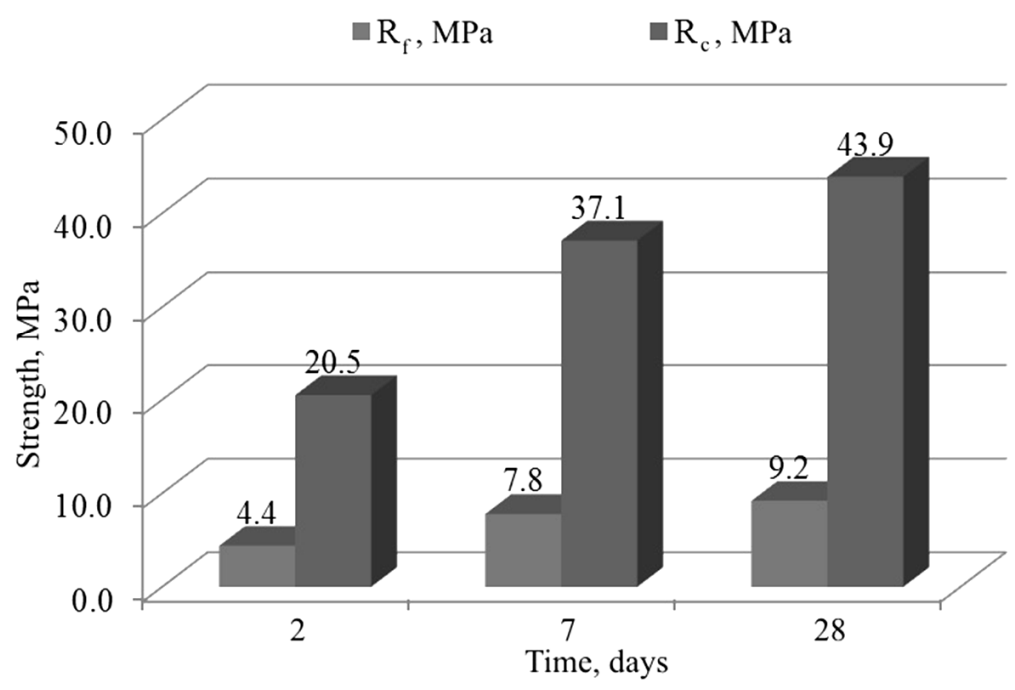

Fig. 4. The effect of adding $1 \%$ basalt scales (BS) to the binder on its physical and mechanical characteristics. 
For the estimation of the effectiveness of reinforcing components on the crack resistance, calculations of the conditional coefficient of crack resistance $\left(\mathrm{C}_{\mathrm{cr}}\right)$ binders were performed, the results are shown in Figure 5.

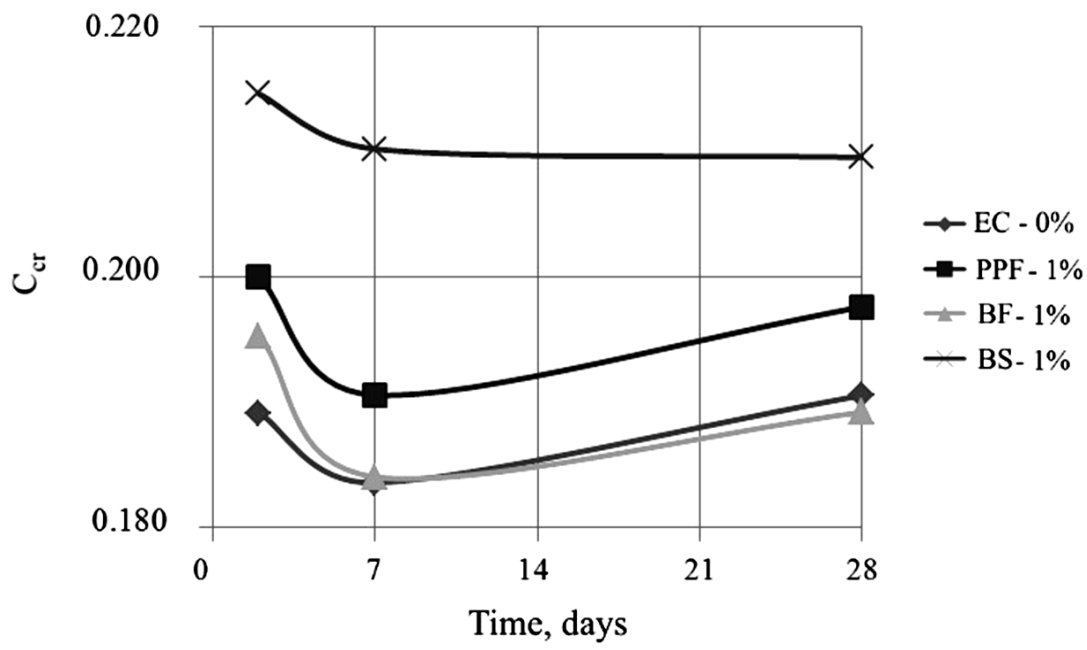

Fig. 5. The effect of adding to the binder of reinforcing components on its coefficient of crack resistance (Ccr).

According to Figure 5 it can be noted that the highest conditional coefficient of crack resistance is characterized by the binder with contents of its composition of basaltic scales, an increase in the coefficient in comparison with the binder without reinforcement of 10$15 \%$. Polypropylene fibers also increase this coefficient by $3-6 \%$; basalt fibers practically do not change the given index, which speaks about its rather low efficiency in relation to increase of cracking resistance of the binder.

For the estimation of the effectiveness of reinforcing components on the crack resistance, calculations of the conditional coefficient of crack resistance $\left(\mathrm{C}_{\mathrm{cr}}\right)$ binders were performed, the results are shown in Figure 5.

a)

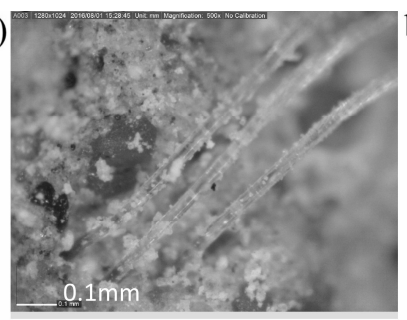

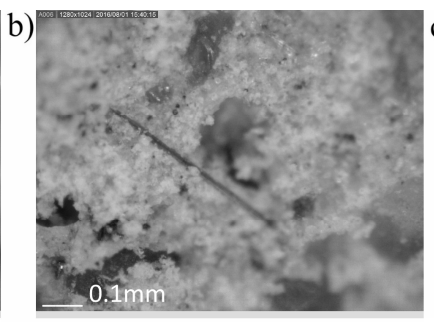

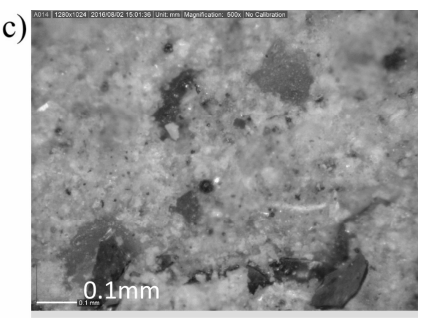

Fig. 6. The Photographs of the microstructure of the binder with $1 \%$ reinforcing components : a) PPF; b) BL; c) BS.

In view of the digital photographs of the microstructure of the binders in Figure 6 , it can be noted that the polypropylene fibers in the binder acts as an inert structure, no contact was found on the contact zone between the fibers and alkaline aluminum silicate. The analysis of the contact zone between the aluminosilicate and the basalt reinforcing components shows that the contact is more dense and the hydrated aluminosilicate tumors are present on the surface of the fibers and scales. The fibers reinforcement occurs only in one direction, while the basalt scales reinforce the composite in two directions, which explains the higher indexes of the cracking resistance of the protective binder. 
Fracture resistance of the binder increases with increasing its ability to withstand tensile stress, while reinforcing the matrix of the binder its strength with bending increases, but deterioration of the mobility of the mortar mixture. Therefore, after analyzing the results of studies on the effect of the type of reinforcing component on the formation of the structure of the binders, it can be noted that the best indicators of physical and mechanical tests and the crack resistance of the binder is characterized by composition with the contents of the basaltic scales. The further research was aimed at determining the effect of the amount of basaltic scales on the flowability of the mortar mixture and the conditional coefficient of crack resistance of the binder, the results of the tests are presented in the graph in Figure 7.

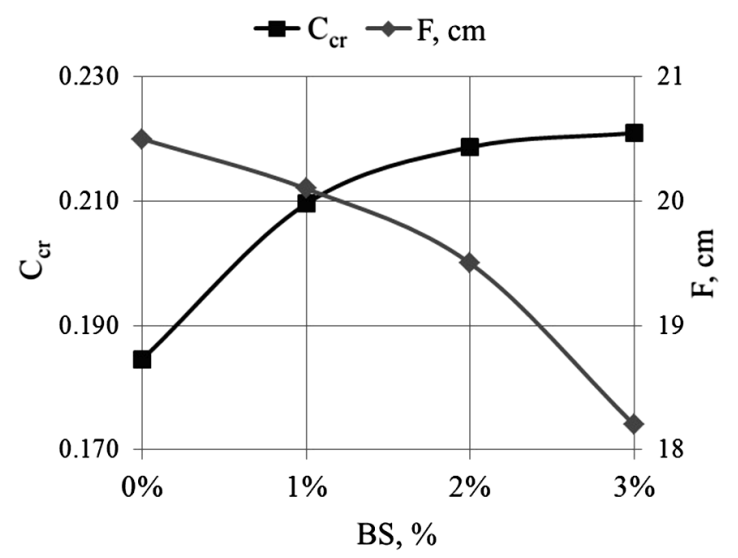

Fig. 7. The effect of the amount of basalt scales (BS) on the flowability (F) of the mortar mixture (F) and the conditional coefficient of cracking resistance of the binder $\left(\mathrm{C}_{\mathrm{cr}}\right)$.

In fig. 7 shows a diagram of the results of the study of effect of the amount of basalt scales on the flowability of the mortar mixture and the crack resistance of the binder. In view of the diagram, it can be noted that a sharp increase in the coefficient of crack resistance occurs when the binder of $1 \div 2 \%$ of the basalt scales is introduced, further increase of its amount leads to decrease of flowability and increase the coefficient of crack resistance of the binder.

\section{Conclusions}

According to the study of influence of type and quality of reinforcing components on the technological and operational properties of alkaline aluminosilicate binders, it should be noted that:

- the addition to alkaline aluminosilicate binder of reinforcing components contributes to the increase of their strength characteristics and the conditional coefficient of crack resistance.

- the highest the conditional coefficient of crack resistance of the protective binder is characterized by the contents containing in its composition as a reinforcing component of the basalt scales.

- the analysis of protective binders microstructure indicates that the contact zone "aluminosilicate binder - basalt scales" is characterized by the highest density.

- the optimum amount for improving the cracking strength of the binder, ensuring the technological properties of the mortar mixture, is $1 \div 2 \%$ of the basalt scales from the weight of alkaline aluminosilicate binder. 
- the further research will focus on the study of operational properties and effectiveness of use of alkaline aluminosilicate binder for the protection of building structures.

The authors express their gratitude to the Ministry of Education and Science of Ukraine for the financial support of work carried out within the framework of budget financing No 1DB-2017, as well as for the development of research topics in the scientific cooperation program COST Action CA15202 "Self Healing building structures: the path to sustainable construction".

\section{References}

1. Stark J., Wicht B. Dauerhaftigkeit von Beton: Der Baustoff als Werkstoff (Weimar, Baupraxis, 2001).

2. Page C. L., Page M. M. Durability of Concrete and Cement Composites (New York, Elsevier, 2007).

3. Mindess, S., Alexander, M., \& Bentur, A. Durability of concrete: Design and Construction (Boca Raton, CRC Press, 2017).

4. Grantham, M., Grantham, M., \& Grantham, M. Concrete repair: A practical guide (London, Routledge, 2011).

5. Bassi, R., Roy, S. K. Handbook of binders for concrete (Latheronwheel, Whittles, 2002).

6. Swamy, R. N., Tanikawa, S. Surface binder for sustainable protection and rehabilitation of concrete structures (Tokyo, Kohbunsha, 2012).

7. Guzii, S., Hela, R., Kirichok, V. Advanced Materials Research, 688, 107-112, (2013).

8. Krivenko, P. V., Guziy, S. G., Kyrychok, V. I. Advanced Materials Research, 923, 121-124, (2014).

9. Kyrychok, V., Drochytka, R., Kryvenko, P. Advanced Materials Research, 1122, 111 114, (2015).

10. Kryvenko, P., Guzii, S., Kovalchuk, O., Kyrychok, V. Materials Science Forum, 865, 95-106, (2016).

11. Kryvenko, P., Kyrychok, V., Guzii, S. EEJET, 5 (83), 40-48, (2016).

12. Schweitzer, P. A. Paint and binders: Applications and corrosion resistance (Boca Raton, CRC Press, 2006).

13. Chung, D. D. L. Composite materials: Science and applications (London, Springer, 2010).

14. Brigante, D. New composite materials: Selection, design, and application (London, Springer, 2014).

15. Omelchuk V., Runova,R., Rudenko I. Key Engineering Materials, 761, 45-48, (2018).

16. Amziane, Sofiane., \& Ferrier, E. Composite Materials Repairs for Reinforced Concrete Structures (Iste, Hermes Science Pub, 2016). 